\title{
Violencia y Teoría Diálogos pendientes en contexto colonial del Pueblo Mapuche ${ }^{1}$
}

\author{
Violence and Theory \\ Pending Dialogues in the Colonial Context of the Mapuche People
}

Pedro Canales Tapia*, Marie Juliette Urrutia Leiva* , Filip Escudero Quiroz ${ }^{* * *}$

\begin{abstract}
Resumen: El siguiente trabajo es un esfuerzo analítico que conjuga los debates en torno a los estudios subalternos en América Latina, con la situación histórica mapuche a partir de un hito que "amenazó" al pueblo mapuche a partir de 1979 en Chile. En función, de una reflexión de doble entrada, profundizaremos en los elementos que configuran un cuadro de violencia política en la Araucanía desde 1997 en adelante. Para esto vinculamos el debate de los estudios subalternos con la situación mapuche reciente. Sostenemos que el colonialismo crea sujetos subalternos racializados, a partir de condiciones materiales que permiten instalar con fuerza este imperativo. Así, la violencia se hace habitual, desde una lógica dominador/dominado; colonizador/colonizado.
\end{abstract}

Palabras Clave: Estudios Subalternos - Colonialismo - Subalternidad - Pueblo Mapuche

\begin{abstract}
The following work is an analytical effort that combines the debates about subaltern studies in Latin America, with the Mapuche historical situation from a milestone that "threatened" the Mapuche people since 1979 in Chile. Based on a reflection of double entry, we will delve into the elements that make up a picture of political violence in Araucanía from 1997 onwards. For this we link the discussion of subaltern studies with the recent Mapuche situation. We argue that colonialism creates racialized subaltern subjects, based on material conditions that allow this imperative to be installed with force. Thus violence becomes habitual, from a dominant / dominated logic; colonizer / colonized.
\end{abstract}

Keywords: Subaltern Studies - Colonialism - Subalternity - Mapuche people

Recibido: 18 mayo 2018 Aceptado: 28 junio 2018

\footnotetext{
1 Este trabajo es parte del Proyecto de investigación interna FI-UVM, “Violencia en la Araucanía” (2016-2017), financiado por la Universidad Viña del Mar.

* Chileno. Coautor. Doctor. Docente Universidad Viña del Mar. mail: pcanales@uvm.cl

${ }^{*}$ Chilena. Coautora. Licenciatura de Historia. Universidad de Santiago de Chile. mail: marie.urrutialeiva@gmail.com

${ }^{* * *}$ Chileno.Coautor. Pedagogía en Historia y Cs. Sociales. Universidad Viña del Mar. mail: escudero.filip@gmail.com
} 


\section{Presentación}

La violencia en la Araucanía se ha tomado la agenda noticiosa en Chile desde hace varios años, y cada vez más también en Argentina. En el caso chileno desde los sucesos de Lumaco en 1997 con nitidez ${ }^{2}$. ¿Los motivos? Para los medios de comunicación, el centro noticioso está en lo que ellos denominan "conflicto mapuche" y en la "violencia" que nace de este. Sin embargo, este esquema simplista y antojadizo, debe ser superado, y abordarlo desde la complejidad histórica. ¿Cuál ha sido la plataforma teórica sobre la cual se ha debatido en torno a esta violencia en el antiguo territorio mapuche?

El quehacer historiográfico -desde su institucionalización hasta nuestros días- ha experimentado una serie de cambios epistemológicos y metodológicos ${ }^{3}$. Es así como podemos ver la emergencia de diversas escuelas o corrientes historiográficas y teorías, las que se desarrollan en respuesta a las críticas de los paradigmas previos. Como diría Iggers, todos estos cambios teóricos "han conducido a un aumento y a una mayor diversidad de interpretaciones; también al reconocimientos de que en la historia no hay repuestas finales sino que un diálogo continuo" ${ }^{\prime 4}$. No obstante, una constante en estos cambios es la preocupación por el pasado y por el sujeto-individuo-sociedad-grupo humano que miramos para reconstruir dicho momento histórico. Tal como sabemos desde el siglo XIX hubo una constante preocupación de parte de la Historia por los grandes hombres políticos y las instituciones, en donde ésta disciplina fue una herramienta para el proyecto nacional específico. Con el correr del tiempo, el centro de atención cambió, el foco se centró en otros sujetos, aquellos desfavorecidos, marginados.

En este diálogo continuo, emerge una perspectiva novedosa a la hora de pensar en los sujetos populares, en aquellos sujetos que hasta el momento seguían sin voz. En los albores de los años 80' del siglo XX un grupo de pensadores del sur de Asia liderados por Ranajit Guha fundan una revista llamada Estudios Subalternos: escritos sobre la historia y la sociedad india, medio que marcó el puntapié inicial en la influencia que estos académicos/teóricos dieron al oficio de historiar. El Grupo de estudios subalternos es un proyecto abiertamente académico y político a la vez; político en el sentido de que busca develar por qué ha sido invisibilizada la agencia de los sectores marginales o como ellos denominan, los subalternos. Entendiendo que dicha subalternidad también se reproduce dentro de las mismas investigaciones historiográficas. El Grupo de estudios subalternos comprenden que estos sujetos sí poseen un rol político dentro de las sociedades en la que se desenvuelven. Nuevas preguntas instalaron allí estos intelectuales indios: ¿qué ocurre con aquellos que siguen quedando fuera de la historia, a pesar de las notables transformaciones historiográficas que se iniciaron a partir de la segunda mitad del siglo XX? ¿Por qué siguen existiendo sujetos olvidados por la Historia? ¿Qué hacer con/para

\footnotetext{
2 Ver Fernando Pairican. Malón. La rebelión del movimiento mapuche. 1990-2013. Santiago, Pehuén ediciones, 2015.

3 Pedro Canales. Tierra e Historia. Estudios y controversias en torno a la historia mapuche en Chile. 1950-2010. Chile, ULS ediciones, 2014, 20.

4 Georg Iggers, La historiografía del siglo XX; desde la objetividad científica al desafio postmoderno, Chile, FCE, 2012, 261.
} 
ellos? ¿Cómo trabajar la fuente, en el entendido de que las fuentes oficiales no son realizadas por los sujetos subalternos, ni menos pensadas para un ejercicio intelectual posterior?

En el presente trabajo queremos elaborar una aproximación al arribo de los estudios subalternos a América y su influencia en el devenir de las ciencias sociales hacia fines de la década de los $80^{\prime}$ del siglo $\mathrm{XX}^{5}$, toda vez que -entre varios otros- el movimiento mapuche y sus reivindicaciones en el sur del continente, comenzaban a visibilizarse y poner ideas en la mesa del debate.

Problematizaremos esta influencia, ya que sostenemos que no podemos homologar dicha irrupción intelectual/teórica y agruparlos en sectores geopolíticamente determinados, pues advertimos que hay distintos intereses en pugna entre los diversos sectores de la academia. Sostenemos que existe un constante diálogo político-intelectual entre académicos de Estados Unidos, los cuales han sido catalogados como las epistemologías del norte, y los intelectuales andinos o las también llamadas epistemologías del sur. Este diálogo se ha trasformado en diferencias académicas y políticas evidentes. Cuestiones claves a la hora de hacer una reflexión históricas acerca de los pueblos indígenas en contextos coloniales. Son estas diferencias las que pretendemos identificar y analizar en el presente trabajo a través de los aportes teóricos de Walter Mignolo y Silvia Rivera Cusicanqui. Para luego analizar las contribuciones historiográficas desde y para el Pueblo Mapuche. Proponemos que el diálogo o el debate norte-sur latinoamericano permeó las formas de contribuir historiográficamente y epistemológicamente en las reflexiones históricas en relación al Pueblo Mapuche.

Para cumplir con uno de los propósitos que tiene este escrito, dividimos el trabajo en las siguientes secciones: una primera parte tendrá como objetivo aproximarnos al grupo indio de Estudios subalternos a través de bibliografía especializada, en la segunda sección analizaremos la recepción e influencia de los Estudios Subalternos en Estados Unidos, identificando a uno de sus precursores, para luego -en la tercera parte- identificar y analizar algunas respuestas andinas que se realizan hacia las epistemologías del norte. Concluiremos el presente trabajo con la identificación de un diálogo político-teórico entre algunos pensadores desde y para el Pueblo Mapuche.

\section{Inteligibilidad del debate}

En 1979 el movimiento mapuche en Chile se comenzó a rearticular en contextos de dictadura, con la intención de oponerse a la instauración del decreto-ley 2.568 que dividida las comunidades mapuche vigentes hasta ese instante ${ }^{6}$. Eran tiempos de dictadura militar y se estaba comenzando a implementar el modelo neoliberal desde 1976. El territorio

\footnotetext{
5 Para efectos del trabajo cuando hablamos de Estudios subalternos, nos referiremos al proyecto original pensado por los intelectuales del sur de Asia, al proyecto político e intelectual. Hacemos la aclaración pues en múltiples artículos y libros en relación al tema se hace una diferencia entre el grupo de historiadores y la revista que lleva el mismo nombre. Sin embargo, este trabajo no tiene como objetivo analizar específicamente dicha revista, sino revisar la trascendencia y la influencia de los Estudios Subalternos en América [latina], éstos pensados en relación a su carácter intelectual y político.

6 Pedro Canales, Memoria y voz mapuche en la creación de la historia. Revista tiempo Histórico. N 5, 2012, 129-144.
} 
mapuche fue uno de los primeros experimentos de esta instauración7. A esta coyuntura, el sociólogo Cristian Vives la denominó como de amenaza para el pueblo mapuche ${ }^{8}$ y criticó fuertemente este decreto-ley, autoritario, mercantilista y contramapuche ${ }^{9}$.

En este contexto temporal, pero en otras latitudes, un grupo de pensadores indios del sur de Asia conformaron el Grupo estudios subalternos. Jóvenes que salían recién de sus primeros estudios universitarios, entre ellos está David Arnold, Shahid Amin, David Hardiman, Partha Chaterjee y Gyanendra Pandey, juventud intelectual liderada por Ranahit Guha, éste último considerado el fundador de los estudios en cuestión. Uno de los acontecimientos más significativos de esta corriente historiográfica -y que por consiguiente marcó el impulso de estos estudiosos- fue la oleada de levantamientos campesinos en la India y la consiguiente represión estatal de Indira Ghandhi, movimiento campesino armado que alcanzó a grandes extensiones de territorios durante la década de los 70', extensión que incluso impactó en una de las fortalezas ideológicas, políticas y sociales del último tiempo: los libros de historia.

El proyecto original de Estudios subalternos fue renovar el quehacer historiográfico con la irrupción de nuevas voces, voces que emergían desde los pueblos colonizados. El objetivo era precisamente rescatar aquellos sectores olvidados por la historiografía, "la constitución de una agenda radical para la historia de la India, que reconociera la centralidad de la agencia de los grupos subalternos (y no tan sólo su presencia) y corrigiera el sesgo elitista de [...] los escritos producidos" ${ }^{\prime \prime}$. Guha re-interpretó el concepto de agencia gramsciano tomando en cuenta las condiciones materiales de la India y las revueltas campesinas que se desarrollaron. La agencia es entendida, para los Estudios subalternos, como la capacidad que estos sujetos tienen en la construcción de sus realidades, en lo cotidianos, en lo público y en lo privado, en la capacidad de transformación, añadiéndole el peso del colonialismo que todas estas relaciones/transformaciones poseen, condiciones colonialistas que Gramsci y otros no pasan por alto, pues ésta es una situación específica de pueblos colonizados. Es, por lo tanto, entregar a los sujetos subalternos su capacidad de agencia, especialmente al campesino. Rompiendo así con la típica concepción historiográfica social que se tiene de estos como masa social, poco unificada, sin consciencia ni menos ideología.

En el caso mapuche del año 79, el agenciamiento surgió a partir de la articulación de los así llamados centros culturales mapuche y posteriormente el surgimiento de Ad mapu como entidades políticas que encabezaron la oposición e Chile y el mundo al decreto-ley que pretendía dividir las comunidades mapuche y principales al servicio del estado ${ }^{11}$. De esta forma fueron resistencia y voces -mapuche y chilenas- que pusieron el dedo "en la llaga" de dicho marco legal. La revista mensaje en Santiago, de origen jesuita,

\footnotetext{
7 Ibíd.

8 Cristian Vives. Mapuche: Pueblo amenazado. Revista Mensaje. № 278, 1979, 230.

9 Ver Cristian Vives. Cristian Vives. Proyecto de ley sobre indígenas: ¿integración o asimilación? Revista Mensaje. $N^{\circ}$ 274. 1978, 713; Cristian Vives. Legislación indígena: eliminación de una cultura. Revista Mensaje. N²90. 1980, 335.

10 Raúl Rodríguez, "Estudios Subalternos revoluciona la historia ("Tercermundista”): notas sobre la insurgencia académica", Raúl Rodríguez Freire (comp.), La (re) vuelta de los Estudios Subalternos. Una cartografía a (des) tiempo, U. Católica del Norte/Ocholibros/Qillqa, 2011, 19.

11 Ad mapu, organización mapuche que lideró resistencia al decreto-ley de la dictadura.
} 
por medio de varios interlocutores, entre los que destacó el sacerdote y sociólogo Cristian Vives, fueron presión para la dictadura, la cual debió matizar la fuerza con la que impulsó esta medida12. También destacó, la figura de Sergio Contreras Navia y Sixto Partzinger, obispos de Temuco y del vicariato Araucanía respectivamente13.

Siguiendo las directrices anteriores, profundizaremos en una de las características principales de estos estudios indios, la cual corresponde al hecho de posicionar al sujeto subalterno, quien puede ser identificado como campesino, mujer, trabajador, etc., como un agente transformador. Esto significa la directa respuesta que hacen hacia los historiadores marxistas británicos. No podemos dejar pasar la crítica de Guha realizada al concepto prepolítico de Hobsbawm. Los movimientos que describe éste, dentro de los cuales están los campesinos, según sus mismas palabras "carece prácticamente de organización o de ideología, y resulta por completo inadaptable a los movimientos sociales modernos. Sus formas más desarrolladas, que lindan con la guerra nacional de guerrilla, se dan poco, y resultan, por sí solas, ineficaces" 14 . En consecuencia, una larga y prestigiosa Historia social o Historia desde abajo, suponen que estos movimientos son abiertamente faltos de política, todos sus actos serían pre-políticos pues no se desarrollan en el contexto de capitalismo, ni mucho menos resisten a él, y, por lo tanto, no han desarrollado una conciencia de clase, es decir, no buscan transformaciones sociales, ni menos romper con la explotación, sino que buscarían sólo justicia social en un mundo tradicional. Tal como vemos, la invisibilización a los sujetos subalternos de la historia no tan sólo la ejerce la historia institucional o nacional, sino también la popular-social.

En el caso de la historia mapuche, los estudios sociales-populares definen a los pueblos indígenas en general como etnias, cuestión compleja a la hora de ver el desarrollo que ha tenido este debate y el derecho internacional indígenas ${ }^{15}$. En cuanto actor político, los indígenas, en este caso los mapuche, siempre fueron entendidos por estas corrientes como campesinos pobres-pauperizados, invisibilizado aspectos culturales, identitarios, religiosas. Asi por ejemplo, siguiendo a Milan Stuchlik, a mediados del siglo XX, el estereotipo de campesino pobre al que había que dar una mano para integrarlo a la nación, será preponderante a la hora de referirse a este pueblo ${ }^{16}$. En general, estos estudios ignoraron $\mathrm{u}$ omitieron la tradición política de este pueblo. Consignemos sólo en el siglo XX, la fundación de varias e importantes organizaciones políticas mapuche como al Sociedad Caupolicán Defensora de la Araucanía (1910), la Federación Araucana (1916) y la Unión Araucana (1920)17. Así también, entre 1924 y 1973, los mapuche contaron con diputados en el Congreso chileno ${ }^{18}$; además de la presencia de la Corporación Araucana

\footnotetext{
12 La Revista Mensajes antes citada en este trabajo, fue un medio de circulación nacional que denunció el alcance de este decreto-ley. El ya citado Cristian Vives fue voz autorizada en este sentido.

13 Transformaciones en la situación social en la población mapuche. Informe de Arturo Leiva para CEPAL, 1985, 1-77.

14 Eric Hobsbawm, Rebeldes primitivos. Estudios sobre las formas arcaicas de los movimientos sociales en los siglos XIX y XX, Barcelona, Crítica, 2001, 16-17.

15 Ver Víctor Toledo Llancaqueo, Pueblo mapuche. Derechos colectivos y territorio: desafíos para la sustentabilidad democrática, Lom, Santiago, 2006.

16 Ver Milán Stuchlik, Rasgos de la sociedad Mapuche contemporánea. Santiago, Ediciones Nueva Universidad, 1974.

17 Rolf Foerster y Sonia Montecino. Organizaciones, líderes y contiendas mapuche. Chile. CEM, 1988.

18 Pedro Canales. "Diputados mapuche”, Revista Estudios Trasandinos. N 17. ULAGOS. Osorno. 2012.
} 
(1938) que operó como un partido político mapuche, destacando ahí Venancio Coñoepan, Diputado y Ministro de Tierras y Colonización, entre otros cargos y proyectos ${ }^{19}$.

Según Dipesh Chakrabarty, quien es parte de los Estudios subalternos desde 1984, no es posible sostener la condición pre-política para pueblos en donde el desarrollo histórico ha sido diferente. Pensando en el caso de la India, el capitalismo se desarrolló de una manera distinta, incluso el autor lo llama capitalismo feudal, por lo tanto, las condiciones de revueltas y los actos por transformación no responden a las mismas lógicas en las que escribe Hobsbawm y quienes lo acompañan, sino que responde a condiciones coloniales de opresión. En consecuencia, siguiendo a Chakrabarty hay un rechazo de parte de los Estudios Subalternos a la "caracterización de la conciencia campesina como pre-política, evitando los modelos evolutivos de la 'conciencia', Guha estaba en condiciones para sugerir que la naturaleza de la acción colectiva contra la explotación en la India colonial extendió eficazmente los límites imaginarios de la categoría "política"20. Ranajit Guha redefine el concepto político, y advierte que todas las insurgencias campesinas que para la 'historia desde abajo' significaban cuestiones arcaicas, en el contexto indio corresponden a luchas claramente políticas. En este sentido, los campesinos no son una conciencia atrasada, sino que un sujeto que resiste a la dominación, resistencia abiertamente política.

Tal vez, en lugar de proporcionarnos una corriente fluida de palabras, obligará a la narrativa a balbucear en su articulación; tal vez la linealidad de su progreso se disolverá en nudos y enredos; tal vez la cronología misma, la vaca sagrada de la historiografía, será sacrificada en el altar de un tiempo caprichoso [...] es que el derrocamiento del régimen de la narratología burguesa será la condición de esta nueva historiografía sensibilizada ante la sensación contenida de desespero y determinación [..] en la voz de una subalternidad desafiante comprometida a escribir su propia historia ${ }^{21}$.

El autor de las palabras que nos precedían es Guha en una de las conferencias inaugurales de los Estudios Subalternos, páginas trascritas llenas de desafíos que apuntan al derrumbe de la narratología burguesa, haciendo una invitación a aquellos subalternos desafiante a escribir su propia historia. Historia no concebida como una narración de corte estatal ni mucho menos ordenada por un tiempo lineal e inequívoco. La cita anterior es la verbalización del proyecto del grupo intelectual indio, es un proyecto historiográfico que busca desligarse de las narraciones estatales, romper con las historias oficiales, identificar las historias que quedaron fuera del tiempo lineal, aquellas marginadas, las que se desarrollan a destiempo.

\footnotetext{
19 Ver José Ancan. Venancio Coñoepan. Ediciones Usach. Chile. 2010.; Ver, Pablo Mariman. “Coñuepán en el Parlamento de 1947. Argumentos y propuestas de la Corporación Araucana". Liwen, No 5, Temuco: Centro de Estudios y Documentación Mapuche Liwen, 1999.

${ }^{20}$ Dipesh Chakrabarty, "Estudios subalternos e historiografía postcolonial", Raúl Rodríguez Freire (comp), La (re) vuelta de los Estudios Subalternos. Una cartografía a (des) tiempo, U. Católica del Norte/Ocholibros/Qillqa, 2011, 342.

21 Ranajit Guha, Las voces de la historia, Barcelona, Crítica, 2002, 31-32.
} 
Todo lo anterior, significa también un desafío metodológico. El principal reto es releer las fuentes oficiales, pensando en que éstas no son escritas por sujetos subalternos, y éstos a la vez no aparecen como protagonistas. Los documentos oficiales no están pensados para el quehacer historiográfico posterior, por lo tanto, estos historiadores indios decontruyen la fuente, la desarticulan, para visibilizar al sujeto subalterno, a aquel que no solo desarrolló estrategias de resistencia, sino que también influyó en la política elitista.

En consecuencia, el aporte de los Estudios Subalternos, pese a la famosa crítica de que sólo correspondería a la continuación de la tradición marxista británica, es una narrativa de insurgencia, pues rompe con los paradigmas previos al intentar entregarle una voz protagónica a aquellos que no la tenían, y que sólo eran concebidos como materia de pie de página para las grandes publicaciones. No sólo hablamos de los historiadores positivistas del siglo XIX, sino también de aquellos estudiosos del XX que, deslumbrados por los conceptos de clase, capitalismo, modernidad, han olvidado a aquellos y aquellas que quedan fuera de estas categorías, a los subalternos,

\section{En órbita Latinoamericana}

El decreto-ley 2.568 de marzo de 1979, fue conocido como de división de comunidades mapuche. Pretendía liquidar la propiedad colectiva en el seno de la sociedad mapuche. Varias leyes durante el siglo XX intentaron hacer lo mismo antes, más nunca se concretó con efectividad ${ }^{22}$. La autoridad militar sostenía en esta ocasión, que este era un "sentido deseo" de los mapuche, toda vez que ya no deseaban -según los militares- continuar viviendo en el formato de "tierras colectivas" sino ser propietarios individuales ${ }^{23}$. Los organismos de estado a cargo de llevar a cabo el proceso en las zonas rurales fue Indap, apoyados por la fuerza policial en casos que así fuera necesario ${ }^{24}$.

De manera concomitante, en lo que podríamos denominar el flujo de ideas, los Estudios subalternos experimentaron su apogeo no tan solo en la India sino también en naciones como Estado Unidos. Estos Estudios no sólo traspasaron fronteras teóricas, sino que también nacionales. Debido al creciente fenómeno de la globalización ayudada de la revolución tecnológica lo que permitía la visibilización de la revista Estudios subalternos: escritos sobre la historia y la sociedad india fundada en 1982, la contante participación de los intelectuales indios en universidades estadounidenses, la traducción de los textos fundacionales en inglés y español, lograron que Estudios Subalternos fuese apropiada por intelectuales estadounidenses en 1992.

Si recordamos, en la década de 1990, en Estados Unidos se consolidaba el giro cultural, que impactó a las ciencias sociales en general y a la historia en particular. Con ello se fortalecían los lazos entre historia y antropología, repensando a los actores sociales como agentes transformadores. Así como también, en el contexto latinoamericano, influye la experiencia de la Revolución cubana, hay una crisis de los socialismos reales, fin de los populismos y dictaduras. Es precisamente, en este contexto intelectual y formal, en los

\footnotetext{
22 Foerster y Montecino, op. cit.

${ }^{23}$ Decreto - ley 2.568. marzo 1973, Chile, 1979.

24 Canales, "Memoria... op. cit.
} 
albores de la década de los noventa del siglo pasado en George Mason University ${ }^{25}$ surgen las primeras expresiones de pensamientos subalternos. Si bien es cierto que muchos intelectuales como John Beverly, Robert Carr, Javier Sanjinés y Walter Mignolo, acuñaron los fundamentos originales de los Estudios subalternos, como por ejemplo la misma idea de subalterno, que se interpreta como lo marginal, lo que queda debajo, y la capacidad de agencia que estos tendrían en el contexto latinoamericano, introdujeron interesantes críticas.

La historiografía y ciencias sociales en Chile durante estos años, abordó la temática mapuche, poco a poco, desde dos ópticas preponderantes. Por un lado, los estudios fronterizos, que poco y nada se vinculan con la discusión de los subalternos, sino para denostarlos y negarles historicidad26; y los estudios inter étnicos, encabezados por Rolf Foerster, José Bengoa y Sonia Montecino y trabajos paradigmáticos como Organizaciones, líderes y contiendas mapuche e Historia del pueblo mapuche respectivamente ${ }^{27}$. La primera línea, liderada por Sergio Villalobos y sus trabajos marcadamente xenofóbicos y ofensivos contra la historia mapuche, asumió una especie de retorno de la semántica propia del siglo XIX, bajo la lógica de mapuche flojos, borrachos y pendencieros, fue negando la existencia mapuche, cuestionando su permanencia en el tiempo, toda vez el mestizaje habría terminado por asimilar a este pueblo en la estructura chilena ${ }^{28}$. La otra corriente, se contrapone a los dichos villalobianos y asume que la interetnicidad asume un rico valor en la diversidad, la construcción social y los matices que cada sociedad en el transcurrir del tiempo va asumiendo ${ }^{29}$.

Ahora bien, volviendo a la escuela de la subalternidad, una de las críticas más contundentes que hicieron estos autores fue la necesidad de la incorporación de ideas feministas a los Estudios subalternos, pues esta categoría sería también parte de la subalternidad, consignando La muerte de Chandra de Guha, como texto base a la hora de investigar la temática. Otras re-interpretaciones que los latinoamericanistas formularon se relacionan con la metodología, pues se cuestionaban si realmente puede hablar el subalterno, en esta búsqueda por la voz del subordinado se unieron con el cauce posmodernista, de la deconstrucción de la fuente, es decir, en un análisis de producción de la fuente. "[Florencia] Mallon criticó fuertemente al Grupo de Estudios Subalternos Latinoamericano, señalando lo que a su juicio era un gran punto débil: el ser demasiado textualista" 30 , con ello introducía la notable crítica al advertir que estos estudios colocaban demasiada atención a los textos/fuentes y no a los sujetos subordinados.

Para no alejarnos de nuestro objetivo investigativo, quisiéramos aproximarnos a la contribución de uno de los integrantes del Grupo de estudios subalternos Latinoamericano, intelectual clave a la hora de pensar en el debate postcolonial o mejor

\footnotetext{
25 Rodríguez, op. cit., 47.

26 Sergio Villalobos, Tres siglos y medio de vida fronteriza en Sergio Villalobos, Relaciones fronterizas en la Araucanía, Ediciones PUC, Santiago, 1982.

27 Ver Foerster y Montecino, op. cit.

28 Canales, Tierra e Historia, op. cit., 48.

${ }^{29}$ Canales, Tierra e Historia, op. cit., 48.

30 Rodríguez, op. cit., 53.
} 
dicho de la colonialidad ${ }^{31}$ en la experiencia de América Latina. Nos referimos a Walter Mignolo. Sin antes indicar que los Estudios Subalternos de la India respondieron, como ya lo decíamos, a un contexto específico de revueltas campesinas. Por lo tanto, es esperable que la apropiación que hacen las epistemologías del norte de América también respondan a valorar las voces subalternas que re-emergen en la década de 1990 en el continente. Esta voz es clara y audible, los indígenas se apoderan del espacio público. Razones suficientes tenemos, para sostener que los intelectuales de lo subalterno pongan especial atención a aquellos subordinados por excelencia de América Latina: los indígenas. Recordemos que para esos años se estaba produciendo en México una de las rebeliones indígenas que marcarán un precedente político y social, nos referimos al levantamiento Zapatista del 94', así como también la resistencia de grupos indígenas a nivel latinoamericano en contra de la 'celebración' del quinto centenario de la conquista hispana, y cómo olvidar la premiación de Rigoberta Menchú.

Walter Mignolo, es un académico de suma relevancia al momento de reflexionar en torno las relaciones de poder que se enfrenta el indígena en contextos de globalización y modernidad. Él fue parte del Grupo de Estudios Subalternos Latinoamericanos hasta que el en 2002 éste se desarticuló producto de la heterogeneidad teórica y metodológica del grupo. Sin por ello disolver lo que sería la influencia de los Estudios Subalternos en el devenir de las ciencias sociales en general, y de la Historia en particular. Una de las ideas que ha trascendido en el pensamiento de este autor es que América no se descubrió en 1492, sino que se inventó. Con esta invención de América, Europa se posiciona como centro de poder mundial. Mignolo en arduo diálogo con Enrique Dussel advierten la existencia de que la modernidad parte con la invención de América para legitimar su poderío-ideas recogidas de Edmundo O'Gorman-, pues antes de la existencia de América, Europa era sólo una periferia y no un modelo de referencia. "La Modernidad es justificación de una praxis irracional de violencia"32, en definitiva, tanto América como el concepto de modernidad es un mito de Europa para validar un posición central ante la periferia que en este caso es América.

Como segunda aproximación al pensamiento de Mignolo, podemos señalar lo que él denomina herida colonial, cuestión que no sería otra cosa que las consecuencias del racismo, es la expresión misma de los «condenados de la tierra» de Fanon. La herida colonial "sea física o psicológica, es una consecuencia del racismo, el discurso hegemónico que pone en cuestión la humanidad de todos los que no pertenecen al mismo locus de enunciación" ${ }^{\prime 3}$. Para Mignolo no basta con señalar la existencia de una herida causada por el racismo y por la interiorización del otro, sino que también ofrece una solución, algo así como la cura a aquella herida:

31 Colonialidad, concepto acuñado por Aníbal Quijano, Enrique Dussel, Walter Mignolo, entre otros, para referirse a la condición de los pueblos colonizados, analizándolos en contextos de globalización y modernidad. Véase Edgardo Lander (comp.), "La colonialidad del saber: eurocentrismo y ciencias sociales. Perspectivas latinoamericanas".

32Enrique. Dussel, "Europa, modernidad y eurocentrismo", Edgardo Lander (comp.), "La colonialidad del saber: eurocentrismo y ciencias sociales. Perspectivas latinoamericanas", Buenos Aires, CLACSO, 2000, 29.

33Walter Mignolo, La idea de América Latina. La herida colonial y la opción decolonial, Barcelona, Editorial Gedisa, 2005, 34. 
entre los proyectos políticos que emergen de experiencias distintas, pero simultaneas de la herida colonial. El diálogo intercultural entre comunidades y proyectos subalternos genera luchar interculturales con el Estado y las instituciones que controlan las esferas de lo social: economía, política, sexualidad y género, subjetividad y saber ${ }^{34}$

Invitación a pensar en las relaciones entre culturas, en un diálogo. Hace un llamado a estar conscientes de la colonialidad de las relaciones, de aquella matriz colonial que acuñó Aníbal Quijano, pensar que estas relaciones culturales poseen rasgos de colonialidad, de aquello que partió con el inicio de la modernidad: con la invención de América tras la llegada del hombre blanco. Promotor de famoso "giro decolonial», quien el mismo caracteriza como "la apertura y la libertad del pensamiento y de formas de vida-otras [...] el desprendimiento de la retórica de la modernidad y de su imaginario imperial [...] tiene como razón de ser y objetivo la decolonialidad del poder"35, es decir, como objetivo pensar las relaciones inter-culturales en su matriz colonial. Construir otro tipo de racionalidad. Pensar en clave colonial o como mejor diría Mignolo: "La «colonialidad», entonces, consiste en develar la lógica encubierta que impone el control, la dominación y la explotación, una lógica oculta tras el discurso de la salvación, el progreso, la modernización y el bien común"36.

En consecuencia, con la figura de Mignolo y el grupo de intelectuales fervientes seguidores de lo que denominan matriz colonial -Dussel, Quijano, Walsh entre otros- se inicia una fuerte corriente que centra su atención en los fenómenos de tinte colonial, tensionando las ideas de modernidad y, junto con ello, una respuesta decolonial: el diálogo entre culturas y la respuesta decolonial como epistemología del saber. Pero, ¿serán suficientes estos avances en relación al contexto latinoamericano en el cual escriben? Ciertamente creemos que no.

\section{Descolonización “en la mesa”}

En territorio mapuche al sur del río Bío Bío, durante los años 80’se fueron liquidando las tierras comunitarias, en palabras de los militares. El movimiento mapuche apoyó la vuelta a la democracia en 1989, no obstante, rápidamente se fueron rompiendo las confianzas y el pacto de Nueva Imperial -entre el nuevo gobierno y la dirigencia mapuche- se volvió obsoleto $^{37}$. El movimiento observó que la ley indígena de 1993 era un brazo funcional a los anhelos del capital, pues se entronizaba la idea de que las tierras mapuche eran funcionales a las forestales y otros proyectos de corte extractivista ${ }^{38}$. Asi todo comenzó a cambiar.

\footnotetext{
34 Ibíd., 180.

35 Walter Mignolo, “El pensamiento decolonial: desprendimiento y apertura. Un Manifiesto", Castro Santiago y Grosfoguel (eds.) El giro decolonial. Reflexiones para una diversidad epistémica más allá del capitalismo global, Bogotá, Siglo del Hombre Editores, 2007, 29-30.

36 Walter Mignolo, La idea de América Latina [...], op. cit., 32

37 Ver José Bengoa, Historia de un conflicto, Chile. Planeta, 1999.

38 Ver Pedro Canales, “Ley winka para los mapuche”, Revista Mensaje. № 467, 1998.
} 
Conectando la situación mapuche con el debate teórico que cruza esta propuesta, Silvia Rivera Cusicanqui en una conferencia que realizó en Chile en 2012 sobre las ciencias sociales y la ideología que junto a estas se desarrollan, se refería a las epistemologías del sur: una apuesta por la descolonización. Rivera Cusicanqui una importante pensadora de izquierda, aymara y feminista, vinculada a la línea de pensamiento de estudios culturales latinoamericanos, específicamente a los grupos poscoloniales y subalternos, ha puesto especial atención al estudio de identidades indígenas. Rivera, entre varios aportes, fue una de las fundadoras de los Talleres de Historia Oral Andina (THOA), instancia en la cual eclosionaron agudas publicaciones en cuanto a los proyectos de liberación indígena.

Tal como lo mencionábamos en un principio, lo subalterno y por consiguiente el grupo que se dedica a estos temas influenciados con los Estudios subalternos, han encontrado en América Latina a un sujeto que reúne características elementales para ser pensados, en relación a la condición de subalternidad, tanto en las relaciones colonialescapitalistas-estatales, y su capacidad de acción política, ese sujeto subalterno desafiante por excelencia es el indígena. Silvia Rivera no se queda al margen de dicha proliferación intelectual. Vemos en ella la materialización de la respuesta que han generado las epistemologías del sur hacia los norteamericanos. Cuestión que nos ayuda a evidenciar uno de los objetivos principales del presente trabajo que es identificar la influencia de los Estudios Subalternos en América Latina y sus diferentes apropiaciones, así como también aproximarnos a las diferencias entre ambos polos ideológicos, diferencias que tienen relación con el proyecto de liberación de los pueblos colonizados. En el caso de las epistemologías andinas este proyecto sólo debería ser pensado en clave de descolonización. Este problema no sólo tendría que ver con identificar aquella herida colonial o promover un diálogo entre culturas, aceptando las relaciones de colonialismos existentes, sino que urge descolonizar los saberes y prácticas, todo esto acompañado de un proyecto político: la conquista del derecho de soberanía territorial, la autodeterminación.

Rivera Cusicanqui postula:

Los Mignolo y compañía han construido un pequeño imperio dentro del imperio, recuperando estratégicamente los aportes de la escuela de los estudios de la subalternidad de la India y de múltiples vertientes latinoamericanas de reflexión crítica sobre la colonización y la descolonización. El corolario fue un multiculturalismo ornamental y simbólico, con fórmulas como el "etno-turismo" y el "eco-turismo", que ponían en juego la teatralización de la condición "originaria", anclada en el pasado e incapaz de conducir su propio destino ${ }^{39}$.

Una de las primeras críticas que salta a la luz es hacia el imperio gringo intelectual, como ella le llama. Acusándoles de escribir desde lugares de privilegios, cuestión que éstas epistemologías de norte no cuestionarían y que sólo utilizaron de forma estratégica la influencia de los Estudios Subalternos, pues continúan con la visión imperialista. Sin embargo, creemos que esta es una de las críticas que a nuestro parecer menos peso tiene.

39 Silvia Rivera Cusicanqui, Ch'ixinakax utxiwa : una reflexión sobre prácticas y discursos descolonizadores, Buenos Aires, Tinta Limón, 2010, 58. 
Pues sostenemos que hay una necesidad de superar los purismos raciales que las ciencias sociales y la historia nos han enseñado, distanciarnos de los esencialismos nos ayudará a aportar al proyecto político común entre quienes son indígenas y quienes no lo son. Se trata de "quien capta de mejor forma -dentro de los márgenes teóricos y metodológicos propios de la disciplina [...]- el impacto de la historia junto a otros que genera en sus propia historia, rehaciéndola, robusteciéndola, y/o -por qué no- redefiniéndola" 40 .

En definitiva, no creemos que sólo por el hecho de estar localizados en un espacio geográfico determinado o porque no tengan un acercamiento real hacia los indígenas, cuestión evidente en la producción de textos en inglés acerca del tema, tengan que pedir una suerte de 'permiso académico' para investigar. Creemos que la crítica debe avanzar hacia otro polo, y no quedarse en la pertenencia étnica de un investigador. Pues si la crítica es llevada a los polos de privilegio, muchas y muchos pensadores, formados en la academia universitaria se verían cuestionados, incluso quienes encuentran legitimación por ser de determinado pueblo indígena. La crítica, sin lugar a dudas, debe avanzar hacia el proyecto político y cultural que estos investigadores desarrollan. En relación a este proyecto, advertimos que Silvia Rivera acierta con la crítica. Ciertamente, cuando Mignolo, Canclini y de ahí en más, hablan de diálogo decolonial o entre culturas, provoca resquemores. Pues esto sólo deviene en un diálogo multicultural, cuestión que dista mucho de los proyectos descolonizadores de los pueblos indígenas, el diálogo multicultural es la materialización de la perpetuación de las relaciones coloniales, del racismo y la violencia colonial. La respuesta decolonial que esbozar Mignolo, según Rivera, habría sido una muestra del multiculturalismo, en donde al Estado sólo le interesa introducir cambios menores para que nada cambie. Suprimiendo así, la capacidad de transformación del indígena, suprimiendo la capacidad que éstos tienen a la hora de pensar en los destinos o fututos posibles en su condición de colonizados.

No puede haber un discurso de la descolonización, una teoría de la descolonización, sin una práctica descolonizadora. El discurso del multiculturalismo y el discurso de la hibridez son lecturas esencialistas e historicistas de la cuestión indígena [...] Su función es la de suplantar a las poblaciones indígenas como sujetos de la historia, convertir sus luchas y demandas en ingredientes de una reingeniería cultural y estatal capaz de someterlas a su voluntad neutralizadora ${ }^{41}$

Creemos que una de las principales diferencias entre las epistemologías del sur y las del norte, y que por consiguiente se trasforma en uno de los debates de mayor prolongación, tiene relación con la descolonización. Es mucho más que identificar diferencias raciales entre unos y otros intelectuales, sino que son diferencias metodológicas y también políticas. Sabemos que la Historia es una disciplina con alto componente ideológico-subjetivo, en donde los investigadores imponen en ésta sus sellos ideológicos. Característica que se hace evidente cuando leemos las dos visiones aquí expuestas. La crítica principal desde las epistemologías andinas es lo que Silvia Rivera Cusicanqui resume en pocas palabras: «No puede haber un discurso de la descolonización, una

\footnotetext{
40 Canales, Tierra e Historia. op. cit, 35.
}

41Rivera Cusicanqui, op. cit., 62. 
teoría de la descolonización, sin una práctica descolonizadora». Practica descolonizadora que se traduzca en una emancipación, en el reconocimiento de un derecho por la soberanía de los cuerpos, saberes, territorios y gentes. Reconocimiento de la extensa historia de colonialismo, ése último definido en tanto tiene por objetivo hegemonizar a distintas particularidades dentro de un todo. Pues el colonialismo no debe ser entendido sólo como los residuos de lo que quedó con la invasión de los Estados nacionales, sino que debe entenderse en su prolongación en el tiempo a través de una ideología colonial. Es por esto que Rivera Cusicanqui dice que las modas teóricas pasan, refiriéndose a los imperios de producción intelectual norteamericana, pues teorías hay muchas y seguirán produciéndose, pero el colonialismo, la realidad que viven los pueblos indígenas, aquellos condenados y olvidados de la tierra, siguen estando dominados por el colonialismo.

Es evidente que hay una estrecha relación entre el colonialismo y la subalternidad en la experiencia latinoamericana en particular. Pues el sujeto que vivió el proceso de colonización y racialización y, que, por lo tanto, lo posiciona como un sujeto subalterno es el indígena, pues las relaciones coloniales lo catalogan bajo lo social. Por lo tanto, la reflexión en cómo los indígenas se trasformaron convirtieron en sujetos subalternos. Para esto veremos la experiencia del Pueblo Mapuche.

\section{Colonialismo y Pueblo Mapuche}

Consignemos que la intencionalidad del decreto-ley contra las tierras mapuche, es parte de una historia mayor: el colonialismo chileno que se inaugura con la invasión a territorio histórico mapuche en el siglo XIX. En 1883 se refunda la ciudad de Villarrica. Este hito no tan sólo significa la instalación de un aparato estatal en territorio mapuche, sino que también simboliza el fin de la guerra que algunos llaman eufemísticamente "Pacificación de la Araucanía". La invasión del ejército chileno significó el despojo de tierras para los mapuche, y la posterior reducción territorial. "El Pueblo Mapuche fue obligado a vivir en reducciones, en tierras de inferior calidad agrícola y ganadera [...] De acuerdo a los datos oficiales, de 9 millones y medio de hectáreas [...] sólo un 5,5\% quedó como propiedad indígena" 42 .

El colonialismo, sin embargo, no sólo queda inscrito en un periodificación histórica, sino que tiene relación con una matriz colonial, una ideología. El colonialismo fue sigue siendo una máquina de despojo cimentada en la violencia. Esta "violencia colonial conlleva el despliegue físico y concreto de una agresión de carácter sistémica y masiva, antecedida por una ocupación e invasión territorial que además se materializa por la vía de cuerpos, gente, seres, máquina y objetos colonizadores" 43 Esta estructura política y social posee múltiples dimensiones y por lo tanto diversos mecanismos de acción. Siguiendo a José Luis Cabrera Llancaqueo "éste [refiriéndose al colonialismo] adquiere una configuración específica dependiendo del espacio geográfico en que se ejecute; y a su

\footnotetext{
42 Pablo Mariman, "Los mapuche antes de la conquista militar chileno-argentina", Pablo Mariman (Ed), "i... Escucha winka...! Cuatro ensayos de historia nacional mapuche y un epílogo sobre el futuro", Santiago de Chile, LOM Ediciones, 2006, 121.

43 Enrique Antileo, Luis Cárcamo, Herson Huinca-Piutrin, y Margarita Calfio (ed), Awükan ka kuxankan zugu wajmapu mew. Violencias coloniales en Wajmapu. Temuco, Ediciones Comunidad de Historia Mapuche, $2015,17$.
} 
vez experimenta reconfiguraciones producto de las trasformaciones políticas que experimentan las sociedades colonizadoras y colonizadas" ${ }^{\prime 4}$. Los contextos políticos, sociales, legislativos, económicos han cambiado en el contexto chileno, y así como estos han sido transformados también lo hace el colonialismo y las herramientas que éste ocupa para su proyecto, éste se amolda, se trasforma y se adapta a los contextos. Cuestión que hace posible que, si avanzamos dos siglos desde la invasión a territorio histórico mapuche, sigamos hablando del peso del colonialismo sobre el Pueblo Mapuche. Jorge Pinto, en este misma línea, sostiene que el estado chileno llevó adelante un sistemático accionar desde la inclusión a la exclusión mapuche, cuestión que se grafica claramente con el enunciado de Cabrera Llancaqueo 45 .

Si tan sólo vemos hoy las relaciones de poder en este territorio histórico, podemos advertir que éstas se configuran/reconfiguran en aspectos raciales. La racialización es el producto del colonialismo. El colonialismo social es aquel que actúa a nivel de las relaciones sociales, marcado por la asimetría entre dominado y dominador, es precisamente una relación de poder, en donde el colonizador se constituye como superior, inferiorizando al colonizado, éste último en su condición de indígena. Al colonizado lo posicionan inferiormente respecto a la hegemonía cultural blanca. Si materializamos esto podríamos encontrar múltiples ejemplos: identificándolo de indio, borracho, pendenciero, y largo etcétera. Es un proceso que afecta al colonizado física y mentalmente puesto que, al catalogar a un individuo de inferior, se le atribuye una racialización, es decir, que por ser de determinada raza debes cumplir tareas dentro de una sociedad. Esta inferioridad a la vez niega la humanidad de estos mismos. No es tan solo violentar a un colonizado, sino que violentar a la colectividad identificada con el grupo.

El debate que inaugura la década de los noventa en Chile con la visibilización del movimiento mapuche tras la coyuntura política de la quema de camiones en Lumaco, irrumpe contra este colonialismo social, dando a conocer que han sido invisibilizados, violentados y categorizados bajo lo social. Fue y sigue siendo un tiempo en donde "el colonizado, por tanto, descubre que su vida, su respiración, los latidos del corazón son los mismos que los del colono. Descubre que una piel de colono no vale más que una piel del indígena"46, interpelar las lógicas coloniales significa el avance hacia el proyecto descolonizador, proyecto que busca conquistar el derecho a la autodeterminación. Así, el estado chileno ha ido implementado estrategias de asimilación, marcadamente violentas y coercitivas contra la población mapuche y sus agrupaciones políticas; los medios de comunicación, por su parte, informan desde la "lógica del colono", y la población criolla en general, abrazan el peso del racismo, estereotipos y frases dañinas. En las cárceles y tribunales vemos sostenidamente a comuneros y comuneras encarcelados a partir de la invocación de la ley antiterrorista diseñada en dictadura y mantenida en tiempos

\footnotetext{
44 José Luis Cabrera Llancaqueo, “Complejidades conceptuales sobre el colonialismo y lo postcolonial. Aproximaciones desde el caso del Pueblo Mapuche”, Revista Izquierdas, N²6, enero 2016, IDEA USACH, 174.

45 Jorge Pinto, El estado, el pueblo mapuche y la nación. De la inclusión a la exclusión, Temuco, UFRO, 2015.

46 Frantz Fanon, Los condenados de la tierra, México, Fondo de cultura Económica, 1963, 39.
} 
democráticos, a pesar de fuerte cuestionamiento a ésta hecha por organizamos internacionales de derechos humanos ${ }^{47}$.

A partir de lo consignado anteriormente, podemos identificar la existencia de la directa relación entre la subalternidad y el colonialismo, ambos conceptos afectan al mismo sujeto: al indígena. En el caso de este trabajo, a los y las Mapuche. Teniendo presente que el hecho de ser un sujeto subalterno o colonizado no niega la capacidad para romper con dicha condición. Pues "si el colonialismo se haya internalizado y alojado en nuestros cuerpos y subjetividades, somos nosotros los que en primer término tenemos la capacidad y el poder de desmantelarlo" 48 .

\section{Conclusión}

A través del presente trabajo, hemos realizado una aproximación a los Estudios Subalternos identificando las influencias de éstos en las epistemologías latinoamericanas. Y la materialización de una ideología colonial que posicionan al sujeto como subalterno en el caso específico del Pueblo Mapuche. Creemos que la llegada de los Estudios Subalternos a los latinoamericanistas, abrió a ellos nuevas perspectivas a la hora abrir el campo metodológico, así como también los sujetos de los cuales se nutría la historia.

Una de las principales continuidades que observamos entre los Estudios Subalternos indios y los latinoamericanistas, es la capacidad de agencia que se le entrega al sujeto subalterno, capacidad política que no era concebida por las corrientes de la historia social de la década de los 80 del siglo XX. Una inflexión que sin lugar a dudas es sumamente importante pues tensiona la idea de que el capitalismo sería la única y más importante forma de explotación, y que sólo en contextos capitalistas industriales se producirían movimientos de conciencia social de trasformación. Pues si miramos la historia latinoamericana, existen formas previas de dominación, dominación de la cual hay sujetos que resisten, movimientos que fuera de estar en contextos plenamente industriales sí son abiertamente políticos. Entendiendo que en Latinoamérica uno de los sujetos subalternos por excelencia fue y sigue siendo el indígena, por lo mismo hay una diversidad de debates y teorías que giran en torno a la condición de colonialidad o colonialismo al que están sujetos.

En consecuencia, con lo anterior, hemos revisado una de las diferencias principales entre los estudios de la subalternidad de Norteamérica, personificado en Walter Mignolo y, otra apropiación andina, que corresponde a las epistemologías del sur, personificado en el pensamiento de Silvia Rivera Cusicanqui. Identificando que la mayor diferencia entre ambos herederos de los Estudios Subalternos, es el proyecto político que los separa: la apuesta por el proyecto descolonizador. Pues no basta con tan sólo reconocer la herida colonial, sino que aportar a su sanación. Curación que no sólo se producirá con el diálogo intercultural, sino que necesita de transformaciones políticas, necesita de un proyecto descolonizador.

47 Ver Víctor Mella, Los mapuche frente a la justicia chilena. Chile, Lom, 2007; Martin Correa y Víctor Mella, Las razones del Illkum. Chile, Lom, 2010; Ruth Vergara, Pewmas/Sueños de justicia, Chile, Lom, 2017, 41-44.

${ }^{48}$ Héctor Nahuelpan, "Las 'zonas grises' de las historias mapuche. Colonialismo internalizado, marginalidad y políticas de la memoria", Revista de Historia Social y de las Mentalidades, V.17, ํo1, 2013, 28. 
Creemos que los Estudios Subalternos son un aporte al debate latinoamericano. Aporte que no sólo se observa en los norteamericanos o en los andinos, sino que sin ir más lejos han sido una influencia en Chile. La creciente historiografía de/para/desde mapuche que ha alcanzado una alta cantidad de investigaciones históricas y antropológicas en los últimos años. Cuestión no azarosa, sino que responde a los contextos de violencia política en la que se ven insertos los indígenas en general y el Pueblo Mapuche en particular. Ahora, nos cabe preguntar si estos intelectuales siguen la senda del diálogo intercultural/multicultural o de los proyectos descolonizadores. Reflexiones necesarias para alcanzar la emancipación de los pueblos colonizados; terreno en el cual la teoría debate en torno a la violencia, y esta interpela con fuerza y decisión la teoría y sus referentes.

\section{Bibliografía}

Cristian Vives, "Proyecto de ley sobre indígenas: ¿integración o asimilación?" Revista Mensaje. № 274. 1978, 711-716.

Cristian Vives," Mapuche: Pueblo amenazado". Revista Mensaje. N² 278. 1979, 229-232.

Cristian Vives, “Legislación indígena: eliminación de una cultura”. Revista Mensaje. № 290. 1980, 334-337.

Dipesh Chakrabarty, "Estudios subalternos e historiografía postcolonial”, Raúl Rodríguez Freire (compilador), La (re) vuelta de los Estudios Subalternos. Una cartografía a (des) tiempo, U. Católica del Norte/Ocholibros/Qillqa, 2011.

Enrique Antileo et al (ed), Awükan ka kuxankan zugu wajmapu mew. Violencias coloniales en Wajmapu. Temuco, Ediciones Comunidad de Historia Mapuche, 2015.

Enrique Dussel, "Europa, modernidad y eurocentrismo", Edgardo Lander (comp.), "La colonialidad del saber: eurocentrismo y ciencias sociales. Perspectivas latinoamericanas", Buenos Aires, CLACSO, 2000.

Eric Hobsbawm, Rebeldes primitivos. Estudios sobre las formas arcaicas de los movimientos sociales en los siglos XIX y XX, Barcelona, Crítica, 2001.

Fernando Pairican, Malón. La rebelión del movimiento mapuche, 1990-2013. Chile, Pehuén ediciones, 2015

Frantz Fanon, Los condenados de la tierra, México, Fondo de cultura Económica, 1963.

Georg Iggers, La historiografía del siglo XX; desde la objetividad científica al desafí postmoderno, Chile, FCE, 2012.

Héctor Nahuelpan, “Las 'zonas grises' de las historias mapuche. Colonialismo internalizado, marginalidad y políticas de la memoria", Revista de Historia Social y de las Mentalidades, V.17, N¹, 2013, 11-33.

José Bengoa, Historia del pueblo mapuche. Chile, Ediciones Sur, 1985.

José Bengoa, Historia de un conflicto, Chile, Planeta, 1999.

José Luis Cabrera Llancaqueo, "Complejidades conceptuales sobre el colonialismo y lo postcolonial. Aproximaciones desde el caso del Pueblo Mapuche", Revista Izquierdas, N²6, enero 2016, IDEA USACH, 169-191. 
Jorge Pinto. El estado, el pueblo mapuche y la nación. De la inclusión a la exclusión, Temuco, UFRO, 2015.

Martin Correa y Víctor Mella, Las razones del Illkum. Chile, Lom, 2010.

Milán Stuchlik, Rasgos de la sociedad Mapuche contemporánea. Santiago, Ediciones Nueva Universidad, 1974.

Pablo Mariman, “Los mapuche antes de la conquista militar chileno-argentina”, Pablo Mariman (Ed), "i... Escucha winka...! Cuatro ensayos de historia nacional mapuche y un epílogo sobre el futuro", Santiago de Chile, LOM Ediciones, 2006.

Pedro Canales, “Una Legislación Winka para los Mapuche”, Revista Mensaje, Marzo-Abril, No 467.

Pedro Canales, Tierra e Historia. Estudios y controversias acerca de la historia del Pueblo Mapuche en Chile, 1950-2010, Chile, Editorial Universidad de La Serena, 2010.

Pedro Canales, "Memoria y voz mapuche en la creación de la historia". Revista Tiempo Histórico. N 5. Chile, UAHC. 2012, 129-144.

Pedro Canales, "Diputados mapuche", Revista de estudios trasandinos, №17. Osorno, ULagos, 2013, 107-118.

Ranajit Guha, Las voces de la historia, Barcelona, Crítica, 2002.

Raúl Rodríguez, "Estudios Subalternos revoluciona la historia ("Tercermundista"): notas sobre la insurgencia académica", Raúl Rodríguez Freire (compilador), La (re) vuelta de los Estudios Subalternos. Una cartografía a (des) tiempo, U. Católica del Norte/Ocholibros/Qillqa, 2011.

Rolf Foerster y Sonia Montecino. Organizaciones, líderes y contiendas mapuche. Chile. CEM, 1988.

Ruth Vergara, Pewmas/Sueños de justicia, Chile, Lom, 2017.

Sergio Villalobos. Tres siglos y medio de vida fronteriza en Sergio Villalobos. Relaciones fronterizas en la Araucanía, Santiago, Ediciones PUC, 1982.

Silvia Rivera Cusicanqui, Ch'ixinakax utxiwa: una reflexión sobre prácticas y discursos descolonizadores, Buenos Aires, Tinta Limón, 2010.

Víctor Mella, Los mapuche frente a la justicia chilena. Chile, Lom, 2007.

Walter Mignolo, La idea de América Latina. La herida colonial y la opción decolonial, Barcelona, Editorial Gedisa, 2005.

Walter Mignolo, “El pensamiento decolonial: desprendimiento y apertura. Un Manifiesto", Castro Santiago y Grosfoguel (eds.) El giro decolonial. Reflexiones para una diversidad epistémica más allá del capitalismo global, Bogotá, Siglo del Hombre Editores, 2007, $25-46$.

\section{Fuente primaria}

Decreto-ley 2.569. República de Chile. Ministerio de Agricultura. 22 marzo de 1979. Transformaciones en la situación social en la población mapuche. Informe de Arturo Leiva Informe CEPAL. Santiago. 1985. 